\title{
Dermatofibrosarcoma Protuberans: Experience at a Third-Level Referral Center
}

\author{
Stefano Caccavale ${ }^{1}$, Adriana Martins Basso ${ }^{2}$, Paola Vitiello ${ }^{1}$, Andrea Ronchi ${ }^{3}$, \\ Antonello Sica ${ }^{4}$, Pasquale Verolino ${ }^{5}$, Ruzica Jurakic Toncic ${ }^{6}$, Giuseppe Argenziano ${ }^{1}$
}

1 Dermatology Unit, Department of Mental and Physical Health and Preventive Medicine, University of Campania Luigi Vanvitelli, Naples, Italy

2 Medicina Integrada, private practice, Sao Paulo, Brasil

3 Pathology Unit, Department of Mental and Physical Health and Preventive Medicine, University of Campania Luigi Vanvitelli, Naples, Italy

4 Oncology and Hematology Unit, Department of Precision Medicine, University of Campania "Luigi Vanvitelli”, Naples, Italy

5 Plastic Surgery Unit, Multidisciplinary Department of Medical-Surgical and Dental Specialties, University of Campania Luigi Vanvitelli,

Naples, Italy

6 Department of Dermatology and Venereology, University of Zagreb, Zagreb, Croatia

Citation: Caccavale S, Martins Basso A, Vitiello P, et al. Dermatofibrosarcoma protuberans: experience at a third-level referral center. Dermatol Pract Concept. 2022;12(01):e2022033. DOI: https://doi.org/10.5826/dpc.1201a33

Accepted: August 14, 2021; Published: January 2022

Copyright: $@ 2022$ Caccavale et al. This is an open-access article distributed under the terms of the Creative Commons Attribution License BY-NC-4.0, which permits unrestricted noncommercial use, distribution, and reproduction in any medium, provided the original authors and source are credited.

Funding: None.

Competing interests: None.

Authorship: All authors have contributed significantly to this publication.

Corresponding author: Stefano Caccavale, MD, Dermatology Unit, Department of Mental and Physical Health and Preventive Medicine, University of Campania Luigi Vanvitelli, Naples, Italy. Email: stefano85med@libero.it

Dermatofibrosarcoma protuberans (DFSP) is a soft tissue sarcoma,a rare and locally aggressive dermal and subcutaneous mesenchymal tumor. DFSP results frequently from the translocation $t(17 ; 22)$ with consequent fusion of the genes of collagen 1A1 (COLL1A1) and of platelet-derived growth factors $\mathrm{B}(P D G F B)$ that activate the signaling of tyrosine kinase [1]. DFSP is usually observed between the third and fourth decades of life. The distribution between sexes is similar, with a slight predominance in females [2]. DFSP typically presents as a slow-growing, reddish-brown plaque, with protruding firm smooth nodules (Figure 1). The most common sites are the trunk and proximal extremities. Usually, it is asymptomatic, being less commonly painful. Immunohistochemical staining is characteristically CD34-positive and factor XIIIa negative. Histopathologic features include a dense dermal tumor, the fascicles of which are interspersed with a storiform configuration, extending to the adipose tissue. Neoplastic cells are monomorphous and have hyperchromatic nuclei [3] (Figure 2).

The treatment is surgical with a clear histological margin. However, the recurrence rate is around $7.3 \%$ for excision with a margin of 2-4 cm. DFSP has low metastatic potential $(2-5 \%)$ but a high rate of local recurrence after surgical excision. Mohs surgery reduces the recurrence rate (about 1\%). Adjuvant radiotherapy can aid in reducing the local recurrence rate [1,3-5]). The use of imatinib reduces the size of 


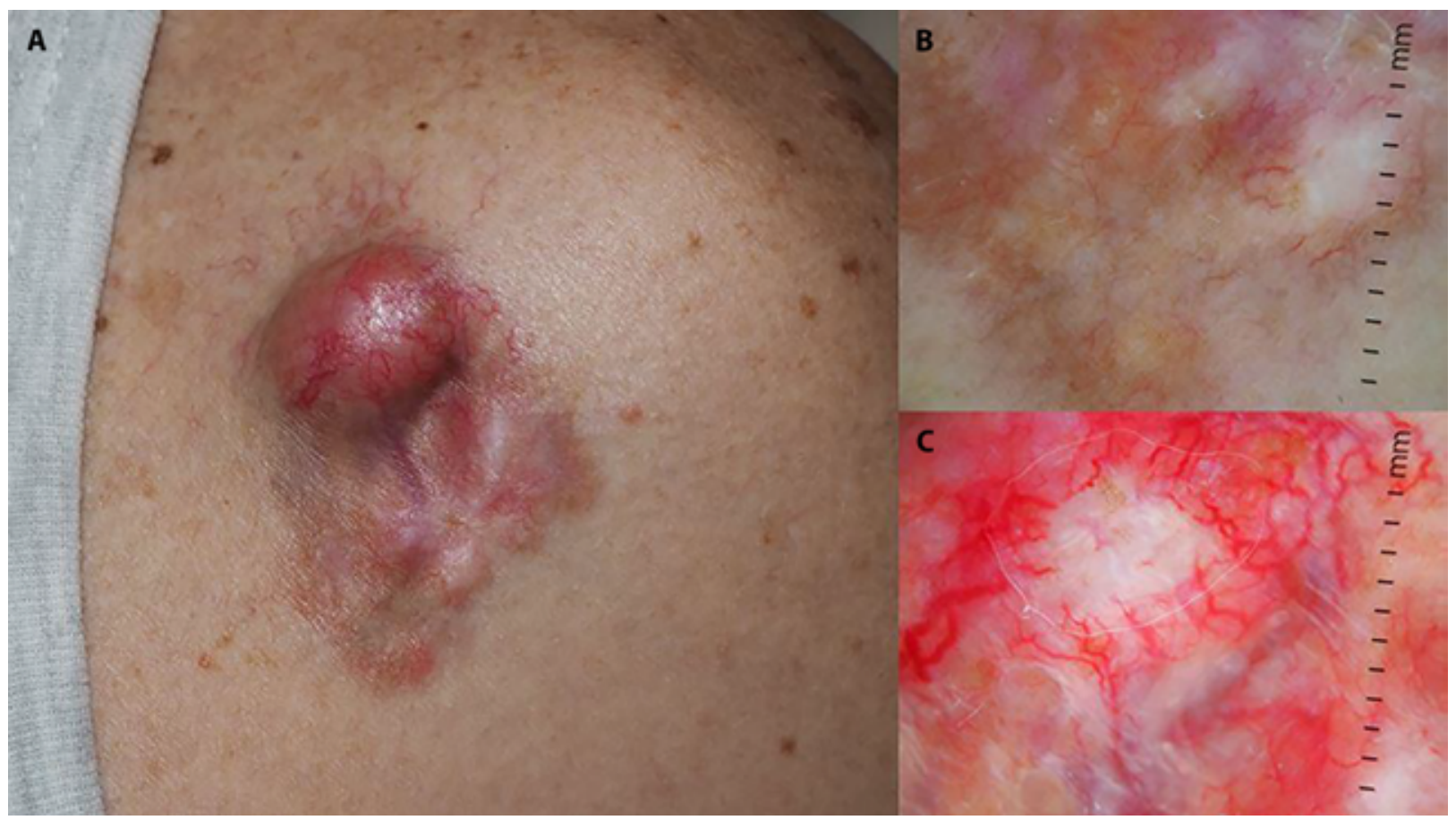

Figure 1. (A) Clinical and (B and C) dermoscopic pictures of a DFSP on a man's deltoid area. On dermoscopy, a brownish or pink background can be seen with a pigment network and arborizing vessels.

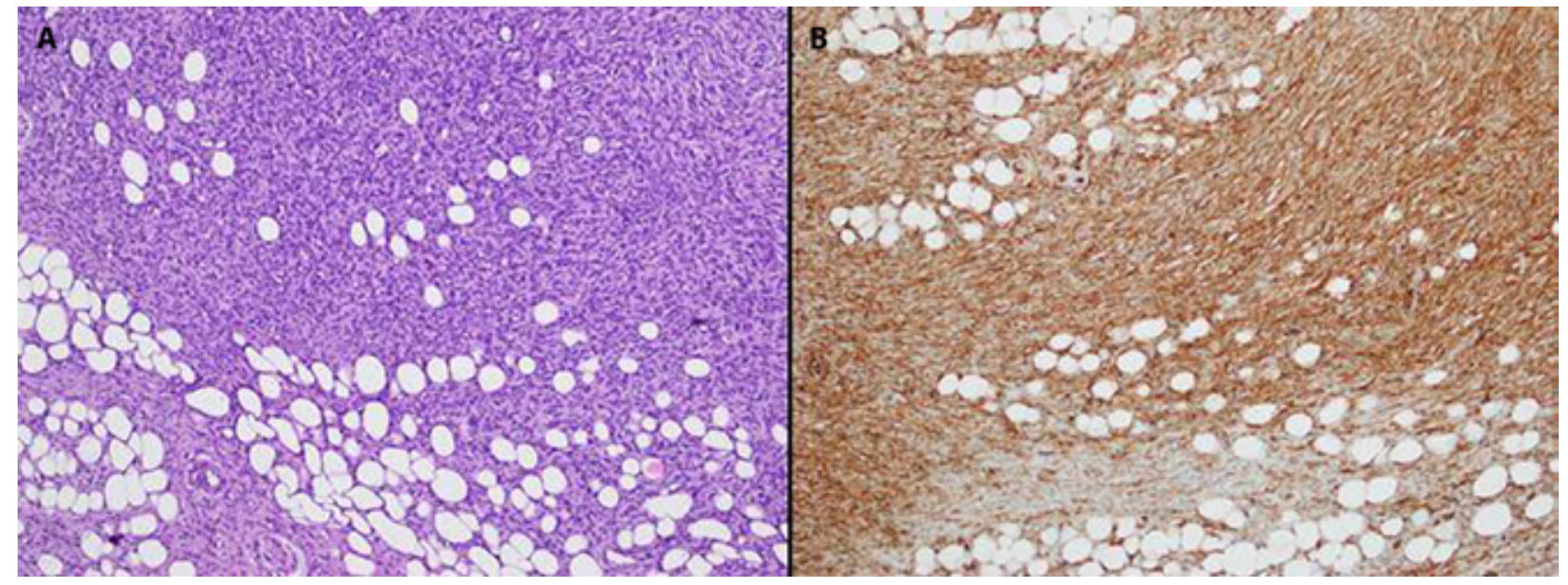

Figure 2. (A) The neoplastic population is arranged in a storiform pattern, entrapping adipocytes. Cells are spindle-shaped with hyperchromatic nuclei (hematoxylin and eosin, magnification $\times 100$ ). (B) The neoplastic cells are positive for CD34 (immunostaining, magnification $\times 100$ ).

inoperable tumors. Follow-up visits are recommended every 3-6 months during the first 3 years [1].

An observational retrospective monocentric study was conducted. The patient list was extracted from the electronic database of the Dermatology Unit of the University of Campania Luigi Vanvitelli, Naples, Italy. Eligible cases affected by DFSP were identified in the retrospective search in the database in the period between January 2006 and November 2020. Cases lacking adequate clinical information (ie sex, age, anatomic site, histopathology) were excluded. We identified 29 cases with a clinical suspicion for DFSP (Table 1). Among them, 21 were confirmed by histological examination (10 men aged 23-68 years at the time of diagnosis, and 11 women 25-79 years old). We found a slightly higher prevalence in females $(52.4 \%)$, in accordance with the literature. The mean age was 44 years for males and 47 years for females. The diagnosis of DFSP was only part of the clinical differential diagnosis in 8 patients (Table 2); the most frequent histological diagnoses in these patients were dermatofibroma and basal cell carcinoma ( $25 \%$ each).

The 21 histologically proven cases of DFSP had involvement of the following body areas: scalp, chest and inframammary, over surgical scar, back, abdomen, upper limb, groin, lower limb, and foot (Table 1). Among these areas, the chest was the most frequently affected by the tumor (33.3\%) followed by the back and abdomen (14.3\%, each).

Six patients did not return after the first visit or after surgery. Some of them had already had a biopsy in another 
Table 1. Body Areas Affected by DFSP in Histologically Proven Cases

\begin{tabular}{|c|c|c|c|c|c|c|}
\hline & $\begin{array}{c}\text { Number of } \\
\text { Cases }\end{array}$ & Female & Age & Male & Age & $\begin{array}{c}\text { Number of Cases for Each } \\
\text { Body Area }\end{array}$ \\
\hline $\begin{array}{l}\text { Histologically } \\
\text { proven cases of } \\
\text { DFSP }\end{array}$ & 21 & 11 & $25-79$ & 10 & $23-68$ & $\begin{array}{l}\text { - } 7 \text { chest } \\
\text { - } 3 \text { abdomen } \\
\text { - } 3 \text { back } \\
\text { - } 2 \text { lower limb } \\
\text { - } 2 \text { upper limb } \\
\text { - } 1 \text { over surgical scar } \\
\text { - } 1 \text { groin } \\
\text { - } 1 \text { foot } \\
\text { - } 1 \text { scalp }\end{array}$ \\
\hline
\end{tabular}

DFSP $=$ dermatofibrosarcoma protuberans.

Table 2. Patients With Clinical Suspicion of DFSP and Their "True” Diagnoses After Histopathologic Examination

\begin{tabular}{|c|c|c|}
\hline & Number of Cases & $\begin{array}{c}\text { Number of Patients for Each Histopathologic } \\
\text { Diagnosis }\end{array}$ \\
\hline Clinical suspicion of DFSP & 29 (21 confirmed with HPE) & 21 \\
\hline $\begin{array}{l}\text { Clinical suspicion of DFSP not } \\
\text { confirmed with histopathology }\end{array}$ & 8 & $\begin{array}{l}\text { - } 2 \text { dermatofibroma } \\
\text { - } 2 \text { basal cell carcinoma } \\
\text { - } 1 \text { invasive melanoma } \\
\text { - } 1 \text { squamous cell carcinoma } \\
\text { - } 1 \text { hypertrophic scar } \\
\text { - } 1 \text { trichilemmal cyst }\end{array}$ \\
\hline
\end{tabular}

DFSP $=$ dermatofibrosarcoma protuberans; HPE $=$ histopathologic examination.

hospital and came to us asking for a second opinion. Among the 13 cases that returned only once for the follow-up visit, 1 patient was also affected by a melanoma and another one returned for management of urticaria. Only 1 patient underwent follow-up controls for more than 5 years.

The number of DFSP diagnosed in our Dermatology Unit between January 2006 and November 2020 is certainly not high, especially when compared to the huge number of patients that we see every day in our third-level referral center. However, as DFSP is a rare tumor, our data are not irrelevant. We have noticed difficulty in monitoring patients because they did not return after evaluation or after surgical removal.

\section{References}

1. McArthur G. Dermatofibrosarcoma protuberans: recent clinical progress. Ann Surg Oncol. 2007;14(10):2876-2886. DOI: 10.1245/s10434-007-9480-y. PMID: 17647063.
2. Mendenhall WM, Zlotecki RA, Scarborough MT. Dermatofibrosarcoma protuberans. Cancer. 2004;101(11):2503-2508. DOI: 10.1002/cncr.20678. PMID: 15503305.

3. Tan AW, Tan SH. Dermatofibrosarcoma protuberans: a clinicopathological analysis of 10 cases in Asians. Australas J Dermatol. 2004;45(1):29-33. DOI: 10.1111/j.1440-0960.2004.00048.x. PMID: 14961905.

4. Ratner D et col. Mohs micrographic surgery for the treatment of dermatofibrosarcoma protuberans. Results of a multiinstitutional series with an analysis of the extent of microscopic spread. J Am Acad Dermatol. 1997;37(4):600-613. DOI: 10.1016/s01909622(97)70179-8. PMID: 9344201.

5. Criscione VD, Weinstock MA. Descriptive epidemiology of dermatofibrosarcoma protuberans in the United States, 1973 to 2002. J Am Acad Dermatol. 2007;56(6):968-973. DOI: 10.1016/j. jaad.2006.09.006. PMID: 17141362. 